\title{
Marine DC resistivity and self-potential survey in the hydrothermal deposit areas using multiple AUVs and ASV
}

\author{
Takafumi Kasaya $^{1,2, *}$, Hisanori Iwamoto ${ }^{2}$, Yoshifumi Kawada ${ }^{2,3}$, and Tadahiro Hyakudome ${ }^{4}$ \\ ${ }^{1}$ Research and Development Center for Earthquake and Tsunami, Japan Agency for Marine-Earth Science and Technology, \\ Yokosuka, Japan \\ ${ }^{2}$ Project Team for Development of New-generation Research Protocol for Submarine Resources, Japan Agency for Marine-Earth \\ Science and Technology, Yokosuka, Japan \\ ${ }^{3}$ International Research Institute of Disaster Science, Tohoku University, Sendai, Japan \\ ${ }^{4}$ Marine Technology and Engineering Center, Marine Technology and Engineering Center Japan Agency for Marine-Earth \\ Science and Technology, Yokosuka, Japan
}

\section{Article history:}

Received 25 March 2019

Revised 29 August 2019

Accepted 2 September 2019

\section{Keywords:}

Autonomous underwater vehicle (AUV), Geophysical exploration, Okinawa trough, Sulfide deposits

\section{Citation:}

Kasaya, T., H. Iwamoto, Y. Kawada, and T. Hyakudome, 2020: Marine DC resistivity and self-potential survey in the hydrothermal deposit areas using multiple AUVs and ASV. Terr. Atmos. Ocean. Sci., 31, 579-588, doi: 10.3319/TAO.2019.09.02.01

\begin{abstract}
Detecting resistivity and self-potential (SP) anomalies is useful for the exploration of hydrothermal deposits. Using autonomous underwater vehicles (AUVs) can increase survey effectiveness because it allows stable posture control without a towing wire cable from a ship. We propose a new style for geophysical surveys using multiple AUVs without a towing electrode cable for marine direct current resistivity (MDCR) and SP survey. We used two AUVs for electrical signal transmission and their receiver. We successfully conducted MDCR and SP surveys in hydrothermal deposit areas using two AUVs with $20 \mathrm{~m}$ tow-rods. One AUV was assisted by an autonomous surface vehicle (ASV) for monitoring and controlling via satellite and the public broadband mobile communications radiowave. The survey covered an area of about 1 square kilometer, spending only 4 hours near the seafloor with the vehicle's speed maintained at $2-2.5$ knots at distance between the AUVs of $200-300 \mathrm{~m}$ during most of the survey. The SP and apparent resistivity were calculated along the main survey line crossing known hydrothermal mounds of sulfide ore. The distribution of the negative SP anomalies obtained in the dive is similar to that obtained from our earlier survey using a deep-tow. The apparent resistivity is generally low $(0.2 \mathrm{ohm}-\mathrm{m}$ or less) above the mounds. The averaged distance between the vehicles and the averaged altitude are respectively about 250 and $70 \mathrm{~m}$. Therefore, the estimated apparent resistivities are the averaged value to several tens of meters below the seafloor. These positions show good agreement with the locations of known hydrothermal deposits.
\end{abstract}

\section{INTRODUCTION}

Resistivity is regarded as an important parameter for the exploration of metallic ore deposits because of the specific electrical properties of metals and metal sulfides. Marine direct current resistivity (MDCR), marine controlledsource electromagnetic (CSEM), and marine transient electromagnetic (TEM) methods are powerful means of exploring these deposits. For example, Hölz et al. (2015) conducted a survey using a towed system with a coincident-loop horizontal transmitter and a receiver loop, and Safipour et al. (2017a) conducted a survey using a vertical

\footnotetext{
* Corresponding author

E-mail: tkasa@jamstec.go.jp
}

coil for the transmission source. Asakawa et al. (2016) and Nakayama and Saito (2016) developed a TEM system of a horizontal coincident-loop and a magnetometer, which are towed below a remotely operated vehicle (ROV). Safipour et al. (2018) proposed a new marine EM system using a TEM transmitter and ocean-bottom electro-magnetometers (OBEMs) deployed to the seafloor as receivers. They successfully detected seafloor massive sulfide deposits.

Recently, the detection of negative self-potential (SP) anomalies has been identified as another important parameter for the exploration of hydrothermal deposits. Kawada and Kasaya (2017) observed electric fields using a deep-tow system with an electrode array along two survey lines across 
known hydrothermal sites. They confirmed that the SP survey detected the subsurface structure of sulfide deposits by tracing the same survey line at different altitudes. Safipour et al. (2017b) obtained horizontal electric field data above a sulfide deposit using an electrometer equipped on their TEM system and detected some negative SP anomalies related to the deposit.

Autonomous underwater vehicles (AUVs), particularly because of their stable posture control without a towing cable, are powerful platforms for scientific investigations and industrial work including the exploration of hydrothermal ore deposits below the seafloor. Kawada and Kasaya (2018) conducted a dense SP survey using a middle-class AUV "JINBEI" as well as mapping turbidity and side-scan sonar data at the same time. They detected a negative SP anomaly related to known hydrothermal deposits that are localized compared to a widely spreading turbidity anomaly distribution. Constable et al. (2018) conducted three-component electric field observations using a commercial AUV (International Submarine Engineering Ltd.) and detected a localized negative SP anomaly.

"Zipangu in the Ocean program", a Strategic Innovation Promotion Program (SIP) managed by the cabinet office of the government of Japan, was launched for the scientific and technological development of natural resources around the Japan Islands to meet expectations of recent national requirements for marine natural resources in Japan. This project encompasses various research fields to assess phenomena including the growth of hydrothermal deposits. Our research group has developed observation instruments and has obtained field data gathered by many means to investigate the relation between the occurrence of hydrothermal deposits and the subsurface structure. Constable (2013) has adopted the style that electric current is transmitted directly to the seawater for the CSEM survey. We also use the same way for a method categorized as MDCR. For this purpose, Goto et al. (2013) developed a system that comprises a transmitter and receiver with an $8 \mathrm{~Hz}$ sampling rate. The transmitter uses an insulated gate bipolar transistor (IGBT) as a precise current transmitting control, with switching devices. Kasaya et al. (2019) reported newly improved transmitters and receivers with $1 \mathrm{kHz}$ sampling loaded on a deep-tow system based on instruments developed by Goto et al. (2013). Our newly developed system, an extension of Kasaya et al. (2019), is also composed of an electrical current transmitter and a receiver to measure the in situ electrical potential. The instruments can obtain both resistivity and SP, respectively using data obtained when the electric current is transmitted and is not transmitted. The very low resistivity zone $(<0.15 \mathrm{ohm}-\mathrm{m})$ associated with the hydrothermal mound area was imaged by the MDCR data in the North Iheya field (Kasaya et al. 2019). Obtaining these two physical parameters simultaneously is extremely beneficial for the survey of hydrothermal deposits. However, towing a long electrode cable from a deep-tow sometimes makes the survey operation difficult in the hydrothermal field with rough topography. The deep-tow system with long towing cable is typically a speed of the 1 knot below, and take over 30 minutes to change next observation line. Therefore, to pursue more efficient survey techniques, we conducted field tests using two AUVs, each equipped with a transmitter and a receiver optimized for use on the AUV, and an autonomous surface vehicle (ASV) for monitoring their condition.

\section{INSTRUMENTS}

\subsection{Outline of Vehicles}

We used AUV "JINBEI" (Hyakudome et al. 2012) as an electric current transmitter and AUV "YUMEIRUKA" (Ohta et al. 2016) as a receiver of electric potential (Fig. 1). These multi-purpose vehicles can accommodate various scientific instruments. A middle-class cruising type AUV "JINBEI", which is $4.0 \mathrm{~m}$ long, $1.1 \mathrm{~m}$ wide, and 1.0 $\mathrm{m}$ high with aerial weight of 1.7 tons, can use its four rear main thrusters to cruise at $2.0-2.5$ knots at a working depth of $3000 \mathrm{~m}$. It has an X-rudder system. Two fore azimuth thrusters contribute to fine vehicle control. The $5.0 \mathrm{~m}$ long, $1.2 \mathrm{~m}$ wide, and $1.2 \mathrm{~m}$ high AUV "YUMEIRUKA" has aerial weight of 2.7 tons. It is characterized by two X-rudder systems: one in the front, and one in the rear. These enable the vehicle body to trace the topographic undulations of the seafloor. Its maximum working depth and cruising speed are, respectively, $3000 \mathrm{~m}$ and 2.5 knots. In addition to deploying these AUVs, an ASV "HubSea" was used to monitor and control AUV "YUMEIRUKA" (Hyakudome et al. 2018). The $4.4 \mathrm{~m}$ long, $1.9 \mathrm{~m}$ wide, and $1.8 \mathrm{~m}$ high ASV weighs 1.8 tons. It can cruise at 3 knots, with maximum speed of 5 knots.

\subsection{Instruments and Survey Design}

Because of payload space constraints and weight limitations in water for AUVs, the transmitter and receiver units should be sufficiently small, with less weight. We developed an improved small transmitter and receiver units for AUV operation based on the original system for a deep-tow system. All electric circuits were redesigned for installation in a pressure case of a small diameter (Fig. 2). The new transmitter system used an IGBT unit as a current control and switching devices. A recorder in the transmitter measures the transmitted electric current data with $250 \mathrm{~Hz}$ sampling rate using 24-bit A/D converter. We prepared an extra battery for the transmitter because we were unable to use the AUV "JINBEI" main battery. These pressure cases were loaded on the fore top of AUV "JINBEI" (Fig. 2). The new receiver unit can record the electric fields in five channels with a 24-bit A/D convertor. The electrometer was improved based on a mobile ocean bottom electrometer (OBE) 


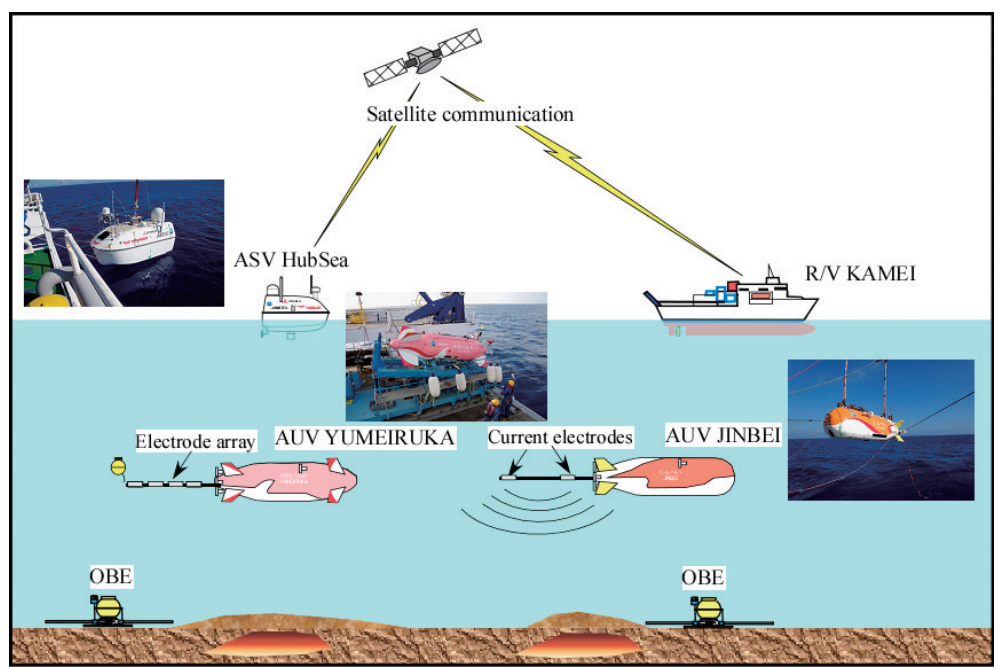

Fig. 1. Conceptual cartoon of exploration using two AUVs and an ASV with photos.
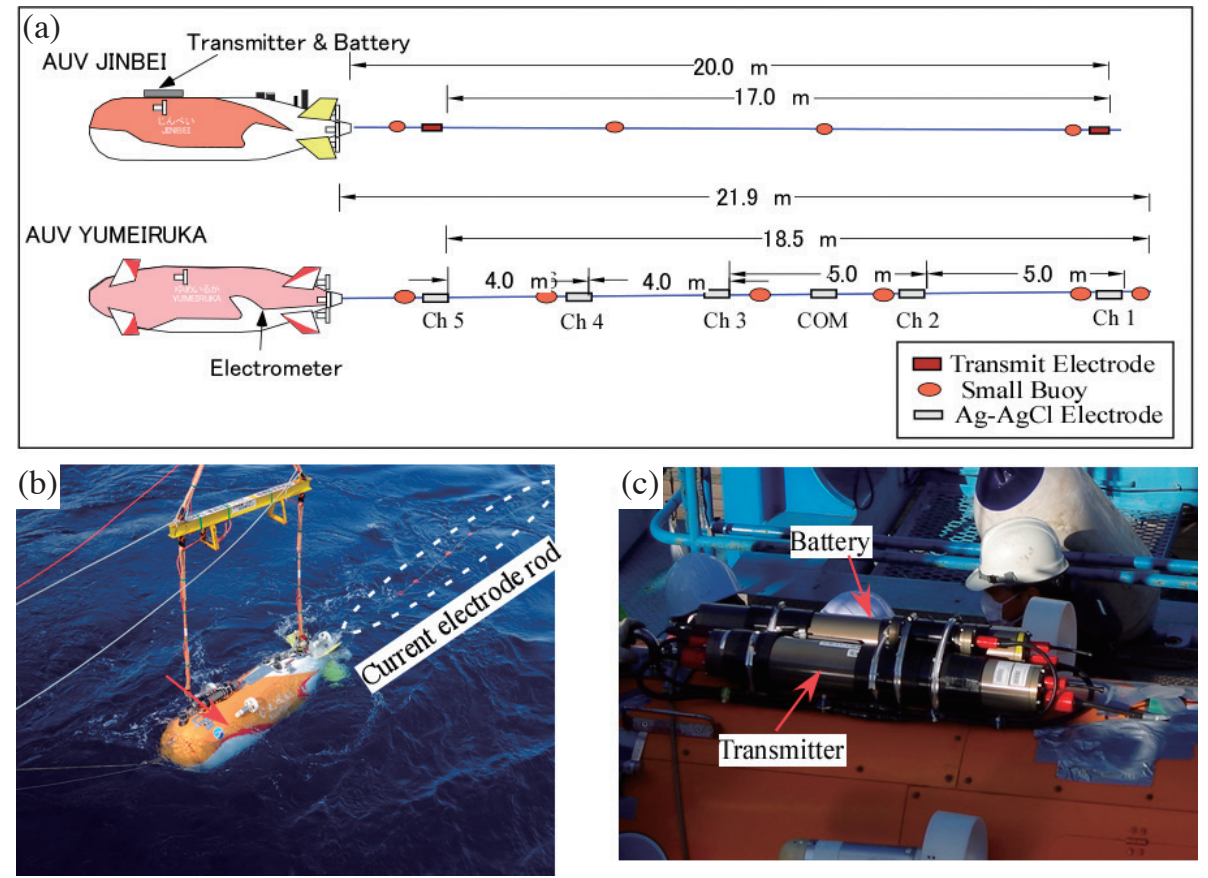

Fig. 2. (a) The electrode and towed rod configuration of each AUV. (b) Photograph of the AUV "JINBEI" before launching with the current rod. (c) Photograph of the instruments on the fore top of AUV "JINBEI". 
system with $1 \mathrm{kHz}$ sampling. The pressure case, including a battery, was installed in AUV "YUMEIRUKA". It is extremely important for active source surveys to synchronize clocks between the transmitted electric current and the received the electric field. Each unit has an atomic clock, which has an accuracy less than 1 millisecond. These clocks are synchronized with high accuracy.

Electrode arrays towed from the AUVs were thin fiberreinforced plastic (FRP) rods to which all electrodes and cabled were attached. The transmitting electrode rod towed from AUV "JINBEI" is a 20-m-long with the electrode interval of $17 \mathrm{~m}$ (Fig. 2). The electrical-signal receiving rod consists of six $\mathrm{Ag}-\mathrm{AgCl}$ electrodes including a common (COM) electrode. Its length is $22 \mathrm{~m}$. The electrode intervals are 4 or $5 \mathrm{~m}$ (Fig. 2). Figure 1 shows a conceptual cartoon illustrating exploration using two AUVs and an ASV. AUV "JINBEI" dives ahead. The AUV "YUMEIRUKA" follows the preceding AUV "JINBEI". For the control of these two AUVs, we used a two line command system. The AUV "JINBEI" is controlled directly from the acoustic communication system of research vessel (R/V) "KAIMEI", a mother ship; AUV "YUMEIRUKA" was monitored and controlled using acoustic communication via ASV "HubSea". The ASV is also controlled from the mother ship by wireless LAN, satellite communication or public broadband mobile communication, which uses very high frequency (VHF) radio wave with the frequency range from 30 to $300 \mathrm{MHz}$ (Hyakudome et al. 2018).

\section{OBSERVATION AND RESULTS}

\subsection{Geological Background of Target Area}

The occurrence of hydrothermal ore deposits in the mid-Okinawa Trough has been reported (Ishibashi et al. 2014). We conducted three practical dives in two hydrothermal deposit areas of the Middle Okinawa trough during 28 to 30 April 2018 on a scientific cruise to assess the areas of hydrothermal deposits (KM18-04C). Before dives in each area, we installed OBEs to test the detection limit of the transmitted signal and to prepare for future MDCR and CSEM analyses. In this paper, we only discuss the preliminary results of AUV's data obtained by an integrated dive at 30 April in the Hakurei field, which is located near the southwestern wall in the Izena hole. We targeted the Hakurei hydrothermal field because it is a well-known hydrothermal deposit (Ishibashi et al. 2014). Extensive results of deep-sea drilling have been reported by the Ministry of Economy, Trade and Industry (METI 2013, 2018). The Japan Oil, Gas and Metals National Corp. (JOGMEC) categorized many large hydrothermal mounds found in the Hakurei field into three groups (Fig. 3). Actually, JOGMEC conducted deepsea coring using a benthic multi-coring system (BMS) and direct sampling using power grab in and around some of the Hakurei field mounds. The mounds were covered by sulfides. Most cored samples obtained from the mound top consist of sulfide. Results of deep-sea drilling by METI (2013) obtained using an onboard drilling machine system indicated a lower sulfide layer below the sediment layer (METI 2013). Later, METI (2018) also found that sulfide minerals from coring samples contain about $1.45 \mathrm{~g} \mathrm{ton}^{-1}$ of $\mathrm{Au}$, on average. The total amount was estimated as about 7.4 megatons.

\subsection{AUVs and ASV Operation}

Before the dive, using bathymetry of the target depth we produced a scenario for each vehicle's altitude along planned survey lines. We checked the safety of each scenario and installed it to each AUV. The ASV has a scenario cruising mode and an automatically AUV track cruising mode. In the scenario cruising mode, we also prepared the ASV scenario, which is consistent with the AUV scenario. With the AUV track cruising mode, the ASV follows the targeted AUV while maintaining distance that can be set via an acoustic telemetry. In our experiments, R/V "KAIMEI" followed AUV "JINBEI". The ASV which installed the scenario followed AUV "YUMEIRUKA".

The ASV was launched in advance to monitor one of the AUV. AUV "YUMEIRUKA" was launched first and descended automatically to the target depth to wait for AUV "JINBEI" to reach the equal depth. Subsequently, AUV "JINBEI" was launched. Each vehicle descended to the target depth with a spiral track because the diving point was near the start point of the survey. After AUV "JINBEI" arrived at the target depth, the survey cruising was started.

To end the survey, serial recovery was conducted for time saving. AUV "JINBEI" was first started to ascend to the sea surface by releasing a ballast weight. AUV "YUMEIRUKA" ascended and maintained $500 \mathrm{~m}$ depth until the AUV "JINBEI" recovery operation was finished. Then, the ballast release command was sent to AUV "YUMEIRUKA" to its recovery operation. Finally, we conducted recovery operations for the ASV.

For valuable MDCR data acquisition, we strove to maintain the distance between the two AUVs at about $250-300 \mathrm{~m}$ and to maintain the vehicle's average altitude at 50 - $80 \mathrm{~m}$ using the command system lines. Figure 4 shows the vehicle's tracks with the bathymetry along the main survey line (see Fig. 3). We were able to control the distance between the vehicles within the target value. As demonstrated, AUV "YUMEIRUKA" was able to follow the fore position of AUV "JINBEI".

\subsection{Data Analysis and Results}

The observed data are a time series of the electric potential of five electrodes relative to a common electrode, the transmitted electric current, and the two AUVs' positions 

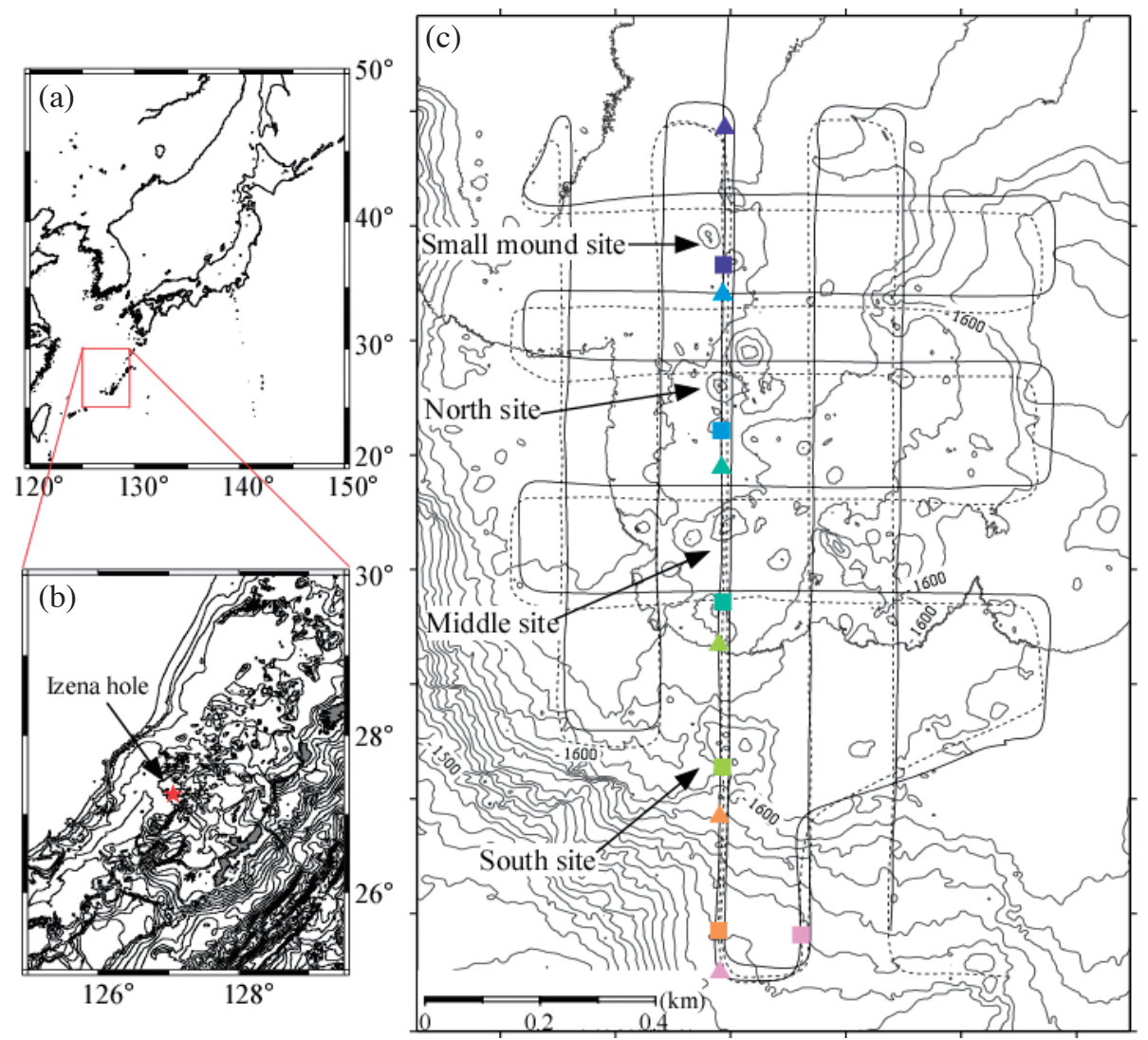

Fig. 3. Maps of the survey area. (a) Regional map around Japan. (b) Map of the mid-Okinawa Trough and the Izena hole location. (c) Map of the study area with dive tracks of two AUVs by acoustic positioning; the thin line and dashed line respectively represent the AUV "JINBEI" and AUV "YUMEIRUKA". Triangles and squares respectively represent the positions of AUV "JINBEI" and AUV "YUMEIRUKA" reported every five minutes. Same color symbols show reported positions at the same time.
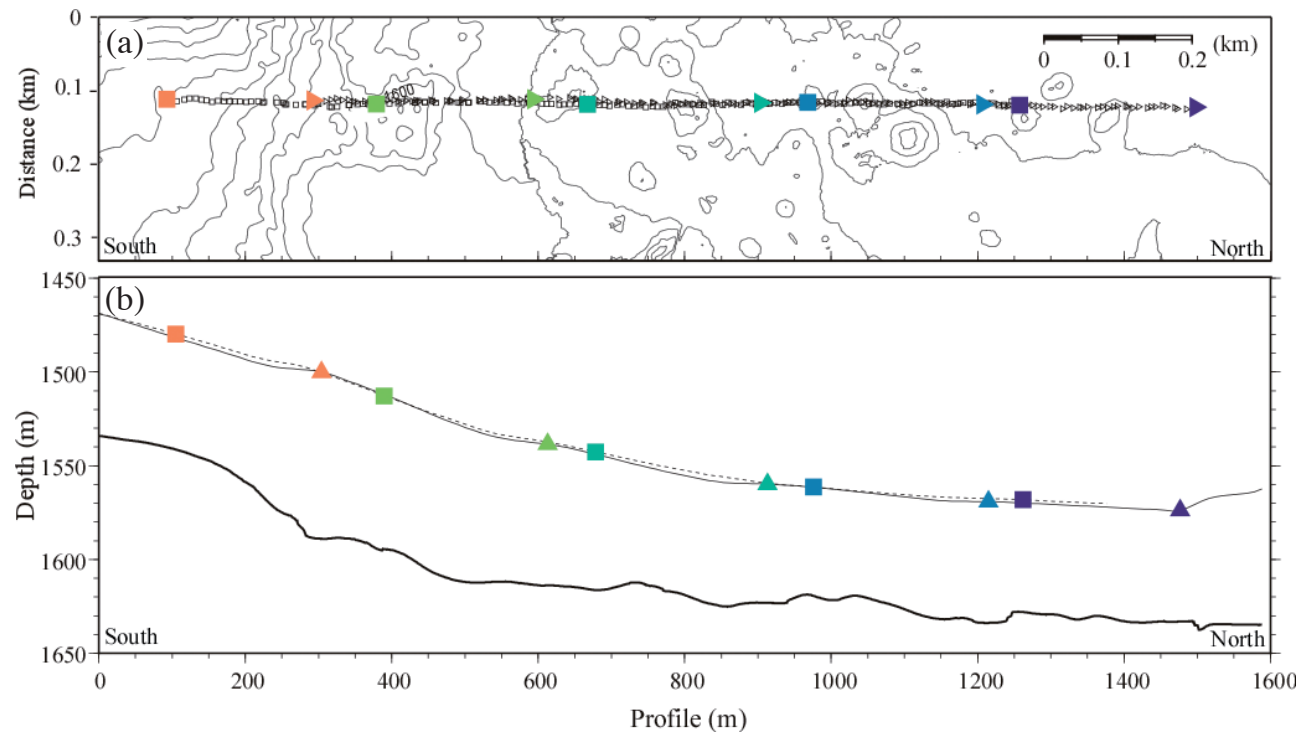

Fig. 4. Vehicle tracks with bathymetry on the main survey line of the third dive (see Fig. 3). Triangles and squares respectively represent the positions of AUV "JINBEI" and AUV "YUMEIRUKA" reported every five minutes. Same color symbols show reported positions at the same time. The thin line and dashed line respectively represent the AUV "JINBEI" track and AUV "YUMEIRUKA" track found by acoustic positioning. 
and altitudes along the dive tracks. Figure 5 portrays an example of time series observed along the main survey line depicted in Fig. 3. A cycle of the MDCR rectangle wave consists of 2-s-long transmission of positive current, followed by 2-s-long suspend, 2-s-long transmission of negative current, and 14-s-long suspend (Fig. 5a). The electric potential data are mixtures of a low-frequency SP component and controlled MDCR rectangle waves.

Kawada and Kasaya (2017) reported that the amplitude of SP anomalies is very large in the Hakurei field of Izena hole. Therefore, the spatial variation of SP anomaly along the survey line must be evaluated carefully. Figure $5 \mathrm{~b}$ presents raw data of electric potential differences of channels 1 - 5. To the raw data, we first applied a low pass filter (a 40-slong Gaussian filter in this study) to remove the MDCR signal. Sometimes, long-period fluctuations and trends were observed in the low-pass filtered time series. In such cases, we subsequently applied a high-pass filter (a 1200-s-long Gaussian filter) to the low-pass filtered time series (Fig. 5c). Then we calculated the electric field by diving the electrode distance and finally obtained the SP by integrating the electric field along the dive track. These procedures were performed for all electrode combinations.

The AUV position (latitude, longitude, and depth) was monitored at every $8 \mathrm{~s}$ using an acoustic navigation system (ANS). Because these data include errors and scatterings, we must remove them. After eliminating outliers from the raw data, time series were interpolated to a 1-s interval by filtering and smoothing operations. For the SP data, we combined the generated position data and the filtered electrical potential data, both of which are resampled in $1 \mathrm{~s}$.

To estimate the apparent resistivity, we applied a highpass filter to the electric potential of each electrode (a 40-slong Gaussian filter in the present study) to remove the SP signals. Then, these time series data are split into every MDCR discharge cycle (30-s-long). The electric potential and transmitted electric current data of every cycle are combined using the time stamp generated by the atomic clocks. In addition, fluctuations and spikes in the potential difference as well as electrode fluctuations caused by towing by the AUV were removed from the data using a low pass filter $(10$ or $20 \mathrm{~Hz})$ and a visual inspection. Figure $5 \mathrm{~d}$ presents the refined data. For each cycle, we calculated V/I for all electrode combinations from the measured potential difference and the recorded electric current via a linear approximation between the voltage and the current. Here, $I$ is the source current amplitude (A), and $V$ is the received voltage (V). Data obtained immediately after the start and the end of power transmission were excluded from the calculation of apparent resistivity because they were adversely affected by the chargeability effect. The apparent resistivity was calculated using the distance separating the two vehicles and the geometry of the current transmitter electrodes and the receiver electrodes. Assuming an infinite space, the appar- ent resistivity was theoretically defined as homogeneous resistivity,

$\rho_{a}=4 \pi \frac{V}{I}\left(\frac{1}{r_{c_{1} p_{1}}}-\frac{1}{r_{c_{1} p_{2}}}-\frac{1}{r_{c_{2} p_{1}}}+\frac{1}{r_{c_{2} p_{2}}}\right)$

where $\rho_{a}$ is apparent resistivity (ohm-m), $r_{i j}$ is distance between electrodes $i$ and $j(\mathrm{~m})$ with subscriptions of $c$ and $p$ being related to the transmitter and receiver electrodes, respectively. In our case, $c_{1}$ and $c_{2}$ are transmitter electrodes in Fig. 2a and a pair of $p_{1}$ and $p_{2}$ is a combination of any two electrodes chosen from the five receiver electrodes in Fig. 2a. For every cycle, the apparent resistivities are obtained from all electrode combinations. After excluding outliers, the apparent resistivities of some combinations (typically ch 1 and 3 , and ch 3 and 5) are averaged at a horizontal position. The horizontal position of the calculated apparent resistivity is defined as the midpoint of the two AUVs. Apparent resistivity points were excluded from the analysis when the distance between the two AUVs was greater than $300 \mathrm{~m}$ because the estimated apparent resistivity values tended to scatter.

Figure 6 shows the calculated apparent resistivity and SP data along the main survey line with the bathymetry. The SP data were calculated by integrating the electric field data along the dive track. Negative anomalies were detected at the three mound sites. The largest anomaly was observed above the south site. A weak negative anomaly was also found at $200 \mathrm{~m}$ north of the north site, designated as the small mound site. The apparent resistivities were calculated using the procedure described above using some combination of channels 1 and 5. The apparent resistivity depicted in Fig. 6 was calculated for the combination of channels 1 and 5 with the best estimation accuracy. Low apparent resistivity $(0.2 \mathrm{ohm}-\mathrm{m})$ was imaged below the active mound sites; apparent resistivities at the north and south ends of the survey line show the same value of seawater resistivity (0.3 ohm-m). A narrow but distinct high apparent resistivity around $0.3 \mathrm{ohm}-\mathrm{m}$ was estimated between the low resistivity of the south and middle sites. In contrast, the low apparent resistivity is continuous from the middle, the north, to the small mound sites, although SP anomalies are not apparent between the mounds.

\section{DISCUSSION AND CONCLUSIONS}

We succeeded in the MDCR and SP surveys in the hydrothermal deposit area using two AUVs with $20 \mathrm{~m}$ towrods assisted by an ASV for monitoring and control of AUV "YUMEIRUKA" via satellite and public VHF broadband mobile communication. As shown by the dive result in the Izena hole portrayed in Fig. 3, we covered an area of about 1 square kilometer during only 4 hours near the seafloor. No major difficulty was found with satellite and public 


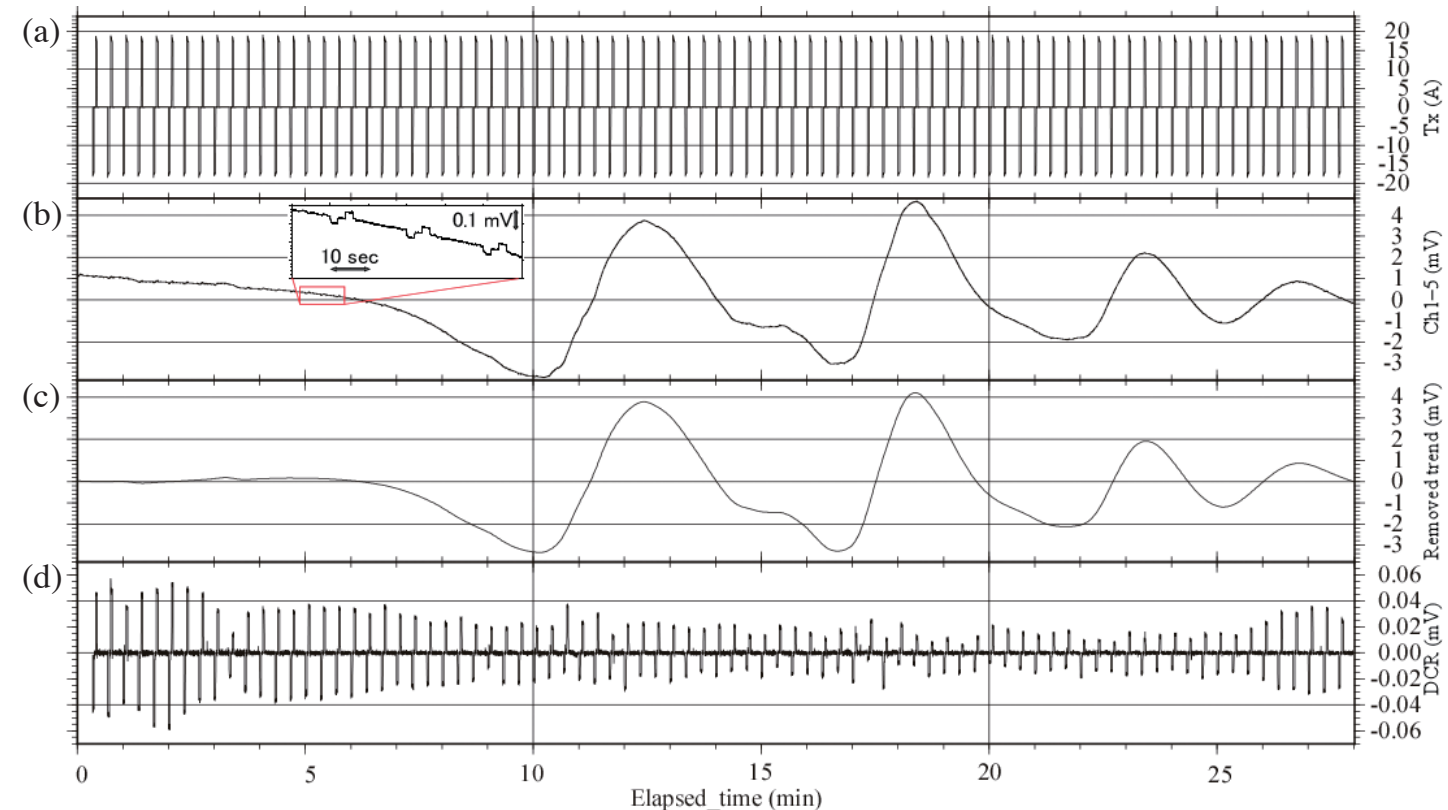

Fig. 5. Obtained time series plots of the main survey line (see Fig. 3). (a) Transmitted current of a transmitter on AUV "JINBEI". (b) Raw time series of electric potential differences of ch 1 - 5 recorded the receiver on AUV "YUMEIRUKA" with inset of the expanded time series. (c) Filtered time series of (b). (d) Extracted MDCR signal from (c).

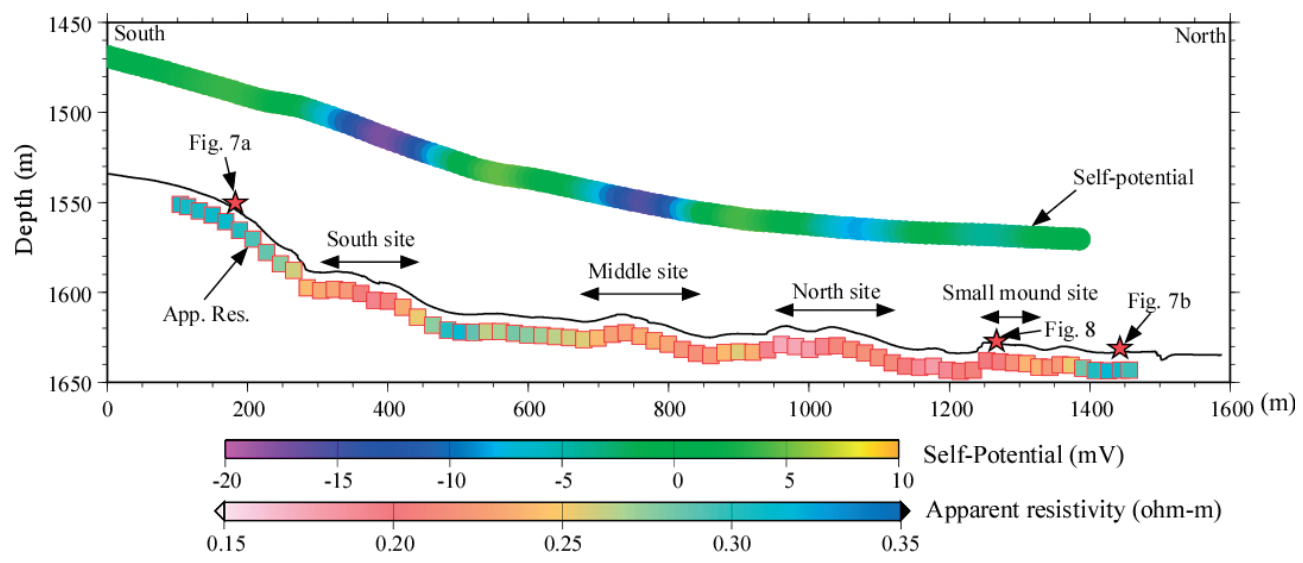

Fig. 6. Apparent resistivities and integrated self-potential data with bathymetry on the main survey line of the third dive (see Fig. 3). Red starts show the position of photos in Figs. 7 and 8. The horizontal position of the calculated apparent resistivity is defined as the midpoint of the two AUVs. 
broadband mobile communications with the ASV during the dive described herein. The distance between the survey lines was about 150 - $200 \mathrm{~m}$. Despite towing electrode rods, the AUVs were able to shift smoothly between these survey lines while maintaining their cooperative operation. The vehicles were able to enter the next survey lines with only 3 - 5 min after the departure of the earlier survey lines. This behavior contributes to efficient use of the survey time. During the dive, the vehicle's speed was controlled to between 2 and 2.5 knots. Figure 4 shows the vehicles' tracks with bathymetry on the main survey line (see Fig. 4). As demonstrated, it was possible to maintain the distance between the AUVs to approximately $200-300 \mathrm{~m}$ during most of the survey. However, because we have not developed the measuring and controlling system of the distance among both AUVs, it is very difficult to maintain the distance control at the beginning of the dive.

The distribution of the negative SP anomalies depicted in Fig. 6 is similar to that obtained using a deep-tow survey (Kawada and Kasaya 2017), which traced about 50 m east of the present survey line. It is a point of particularly good correspondence that the amplitude of the negative SP anomaly is greatest at the south site for both surveys. Kawada and Kasaya (2017) estimated the subsurface current source distribution that explains the SP anomalies. They also reported that it is difficult to explain these SP anomalies by the effects of high-temperature fluids from hydrothermal vents in the water column because the distribution of SP anomalies does not necessarily match those of electrical conductivity and temperature anomalies in the water column obtained by Conductivity Temperature Depth (CTD) sensor. The mechanism of a negative SP anomaly in on-land environments is explained by the geo-battery model (Sato and Mooney 1960), in which an electrically conductive ore body connects different redox states to activate redox reactions. A water table is a boundary between the oxic and reduced environments. In marine environments, a geo-battery model is the reasonable mechanism for negative SP anomalies (Kawada and Kasaya 2017) because of the presence of an electrically conductive ore body in the subsurface redox gradient. The seafloor is a candidate for the boundary between the oxic and reduced environments. In this case, only protruded ore deposits can be detected. If hydrothermal fluid flow, in particular, recharge flow, is present, the boundary might be deepened. Hence, a completely buried ore deposits might be detected, and the SP anomalies observed during the present AUV dives include information about the subsurface structure related to the hydrothermal deposits.

The apparent resistivity is generally low $(0.2 \mathrm{ohm}-\mathrm{m}$ or less) above the hydrothermal mounds. On this survey line, the averaged distance between the vehicles and the averaged altitude are, respectively, about 250 and $70 \mathrm{~m}$. Consequently, the estimated apparent resistivity values are the averaged resistivity to several tens of meters below the seafloor. METI (2013) reported from their drilling results that these mounds mostly comprise sulfides. In general, a resistivity value of sulfides is low (Cairns et al. 1996). We assert that the areas of low apparent resistivity correspond to the sulfide ore body from the survey depth. Data reported by METI (2018) also indicate the existence of deep ore bodies, of which the top is about $30-40 \mathrm{~m}$ below the seafloor. Whether the estimated apparent resistivity detects deep ore bodies remains unclear because of its averaged nature. However, the continuous low resistivity from the middle to the small mound sites coincides with such a sub seafloor structure. Additionally, it is noteworthy that the source depth of SP anomaly is obtained to several tens of meters below the seafloor (Kawada and Kasaya 2017).

Figure 7 presents images of the seafloor near the northern and southern ends of the survey line (Fig. 4) taken by a submersible observation, where high resistivity with no apparent SP anomaly is shown. The seafloor is very flat with many holes and tracks made by benthos. No indication of hydrothermal activity was found. In some places, small rocks can be found on the seafloor. Kawada and Kasaya (2017) observed that volcanic bodies do not generate SP anomalies. Consequently, the areas in the ends of the survey line are resistive volcanic bodies covered by the soft sediments. In addition, an area with low resistivity and weak negative SP anomaly is detected above small mounds found north of the north site (Fig. 8). The possibility exists that small ore bodies are buried below the seafloor in this area as well as small mounds protruding from the seafloor.

When we conducted MDCR and SP surveys with only a 4-hour observation period using two AUVs and an ASV simultaneously, we detected readily apparent anomaly areas related with hydrothermal deposits using two independent parameters: low apparent resistivity and negative SP anomaly. These results demonstrate that geophysical exploration survey using two AUVs is extremely efficient. The present survey covered $1 \mathrm{~km}^{2}$, but took only 4 hours near the seafloor. Consequently, covering an area of more than several square kilometers is expected to be possible by overnight observation if the battery life and capacity were improved. At present, a chief commander must direct all controls to maintain safe and planned distance between the two AUVs. However, if such control could be automated using intelligent control techniques, then more efficient observations could be anticipated.

Acknowledgements This study was supported by the Cross-ministerial Strategic Innovation Promotion Program "Next-generation technology for ocean resources exploration" launched by the Council for Science, Technology and Innovation (CSTI) and managed by the Japan Agency for Marine-Earth Science and Technology (JAMSTEC). The data used for this study are available from the authors upon request. We would like to thank two anonymous reviewers 

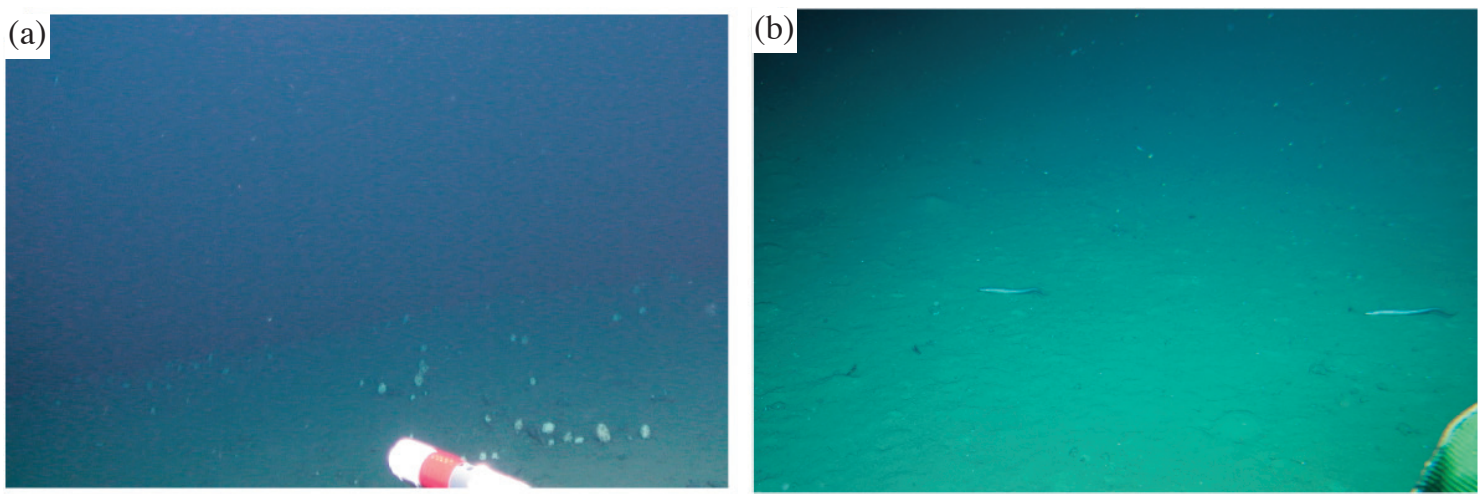

Fig. 7. Pictorial conditions of the seafloor near the southern end (a) and northern end (b) denoted on Fig. 6.

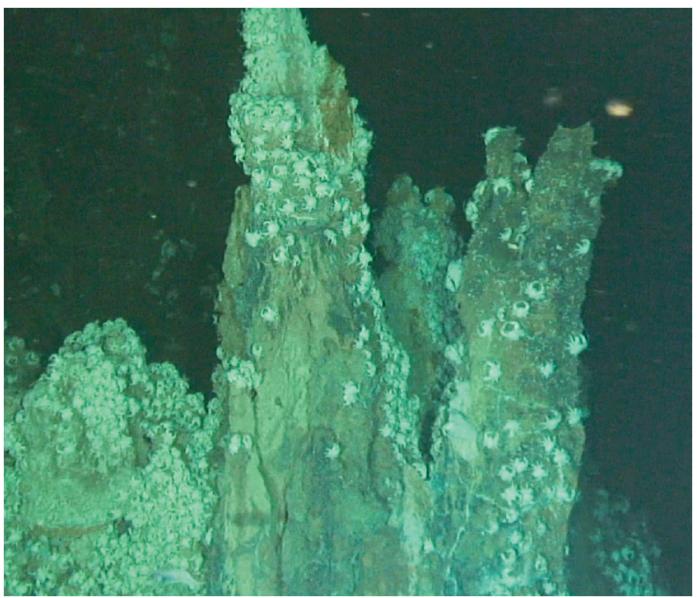

Fig. 8. Photo of some mounds with benthos's communities on hydrothermal vents in the small mound area.

for useful comments. We appreciate H. Yoshida and T. Goto for helpful advices of our study. We thank the captain and crews of R/V "KAIMEI" and marine technicians for assisting the observation during the cruise KM18-04C. We are grateful to the operation team for AUV "JINBEI" and KMROV. We also thank T. Yoshiume, Y. Nanbu, Y. Ohta, Y. Watanabe, H. Matsumoto, H. Ochi, K. Meguro, Y. Nakano, and T. Fukuda for operation of AUV "YUMEIRUKA" and ASV "HubSea". N. Katayama (National Institute of Information and Communications Technology) helped us the satellite communication of ASV.

\section{REFERENCES}

Asakawa, E., T. Sumi, T. Yamakawa, and M. Kose, 2016: Multi-stage and integrated approach for seafloor Massive Sulfide (SMS) Exploration. Near Surface Geoscience 2016 - First Conference on Geophysics for Mineral Exploration and Mining, Barcelona, Spain, European Association of Geoscientists \& Engineers, 1-5, doi: 10.3997/2214-4609.201602110. [Link]
Cairns, G. W., R. L. Evans, and R. N. Edwards, 1996: A time domain electromagnetic survey of the TAG hydrothermal mound. Geophys. Res. Lett., 23, 34553458, doi: 10.1029/96GL03233. [Link]

Constable, S., 2013: Instrumentation for marine magnetotelluric and controlled source electromagnetic sounding. Geophys. Prospect., 61, 505-532, doi: 10.1111/j.13652478.2012.01117.x. [Link]

Constable, S., P. Kowalczyk, and S. Bloomer, 2018: Measuring marine self-potential using an autonomous underwater vehicle. Geophys. J. Int., 215, 49-60, doi: 10.1093/gii/ggy263. [Link]

Goto, T., N. Imamura, H. Mikada, J. Takekawa, T. Kasaya, and K. Sayanagi, 2013: Electromagnetic survey around the seafloor massive sulfide using autonomous underwater vehicle. Proceedings of the 11th SEGJ International Symposium, Society of Exploration Geophysicists of Japan, Yokohama, Japan, 342-345, doi: 10.1190/segj112013-087. [Link]

Hölz, S., M. Jegen, S. Petersen, and M. Hannington, 2015: How to find buried and inactive seafloor massive 
sulfides using transient electromagnetics - A case study from the Palinuro Seamount in the Tyrrhenian Sea. 44th Underwater Mining Conference, Nearshore Underwater Mining: Critical Commodities for the Future, UMC, Tampa Bay, Florida USA.

Hyakudome, T., H. Yoshida, S. Ishibashi, H. Ochi, T. Sawa, Y. Nakano, Y. Watanabe, T. Nakatani, M. Sugesawa, Y. Ohta, K. Watanabe, S. Oomika, Y. Nanbu, and M. M. Komuku, 2012: Development of AUV for scientific observation. Oceans 2012 MTS/IEEE, Hampton Roads, VA, USA, IEEE, 1-4, doi: 10.1109/ OCEANS.2012.6404892. [Link]

Hyakudome, T., H. Matsumoto, Y. Nakano, Y. Watanabe, T. Fukuda, R. Suga, K. Meguro, H. Yoshida, T. Kasaya, and H. Iwamoto, 2018: Development of ASV for using multiple AUVs operation. OCEANS 2018 MTS/ IEEE Charleston, Charleston, SC, USA, IEEE, 1-4, doi: 10.1109/OCEANS.2018.8604850. [Link]

Ishibashi, J.-I., T. Noguchi, T. Toki, S. Miyabe, S. Yamagami, Y. Onishi, T. Yamanaka, Y. Yokoyama, E. Omori, Y. Takahashi, K. Hatada, Y. Nakaguchi, M. Yoshizaki, U. Konno, T. Shibuya, K. Takai, F. Inagaki, and S. Kawagucci, 2014: Diversity of fluid geochemistry affected by processes during fluid upwelling in active hydrothermal fields in the Izena Hole, the middle Okinawa Trough back-arc basin. Geochem. J., 48, 357369, doi: 10.2343/geochemj.2.0311. [Link]

Kasaya, T., T. Goto, H. Iwamoto, and Y. Kawada, 2019: Development of multi-purpose electromagnetic survey instruments. The 13th SEGJ International Symposium, Tokyo, Japan, Society of Exploration Geophysicists and Society of Exploration Geophysicists of Japan, doi: 10.1190/segj2018-042.1. [Link]

Kawada, Y. and T. Kasaya, 2017: Marine self-potential survey for exploring seafloor hydrothermal ore deposits. Sci.Rep., 7, 13552, doi: 10.1038/s41598-017-13920-0. [Link]

Kawada, Y. and T. Kasaya, 2018: Self-potential mapping using an autonomous underwater vehicle for the Sunrise deposit, Izu-Ogasawara arc, southern Japan. Earth
Planets Space, 70, doi: 10.1186/s40623-018-0913-6. [Link]

METI, 2013: Report for the First Stage of the Program, Development of Deep-sea Mineral Resources, 104 pp. Available at http://www.jogmec.go.jp/content/300110684.pdf. (in Japanese)

METI, 2018: Final Report of the Development of Deep-sea Mineral Resource Program, 158 pp. Available at http:// www.jogmec.go.jp/content/300359550.pdf. (in Japanese)

Nakayama, K. and A. Saito, 2016: The seabed TDEM towed by ROV for the ocean bottom hydrothermal deposits. Near Surface Geoscience 2016 - First Conference on Geophysics for Mineral Exploration and Mining, Barcelona, Spain, European Association of Geoscientists \& Engineers, 1-5, doi: 10.3997/2214-4609.201602109. [Link]

Ohta, Y., H. Yoshida, S. Ishibashi, M. Sugesawa, F. H. Fan, and K. Tanaka, 2016: Seabed resource exploration performed by AUV "Yumeiruka”. Oceans 2016 MTS/ IEEE Monterey, Monterey, CA, USA, IEEE, 1-4, doi: 10.1109/OCEANS.2016.7761122. [Link]

Safipour, R., S. Hölz, J. Halbach, M. Jegen, S. Petersen, and A. Swidinsky, 2017a: A self-potential investigation of submarine massive sulfides: Palinuro Seamount, Tyrrhenian Sea. Geophysics, 82, A51-A56, doi: 10.1190/ geo2017-0237.1. [Link]

Safipour, R., S. Hölz, M. Jegen, and A. Swidinsky, 2017b: On electric fields produced by inductive sources on the seafloor. Geophysics, 82, E297-E313, doi: 10.1190/ geo2016-0700.1. [Link]

Safipour, R., S. Hölz, M. Jegen, and A. Swidinsky, 2018: A first application of a marine inductive source electromagnetic configuration with remote electric dipole receivers: Palinuro Seamount, Tyrrhenian Sea. Geophys. Prospect., 66, 1415-1432, doi: 10.1111/13652478.12646. [Link]

Sato, M. and H. M. Mooney, 1960: The electrochemical mechanism of sulfide self-potentials. Geophysics, 25, 226-249, doi: 10.1190/1.1438689. [Link] 